\title{
Le nostre società saranno presto confrontate a nuove sfide
}

\section{Gilbert Dalgalian}

Traduttore: Stefano Corno

\section{(Q) OpenEdition \\ Journals}

\section{Edizione digitale}

URL: http://journals.openedition.org/esp/2089

DOI: $10.4000 /$ esp.2089

ISSN: 2532-0319

\section{Editore}

Centre d'Information sur l'Éducation Bilingue et Plurilingue

\section{Edizione cartacea}

Data di pubblicazione: 1 giugno 2018

Paginazione: $3-4$

ISSN: 1127-266X

\section{Notizia bibliografica digitale}

Gilbert Dalgalian, «Le nostre società saranno presto confrontate a nuove sfide », Éducation et sociétés plurilingues [Online], 44 | 2018, Messo online il 08 février 2019, consultato il 24 septembre 2020. URL http://journals.openedition.org/esp/2089 ; DOI : https://doi.org/10.4000/esp.2089 


\section{EDITORIALE: LE NOSTRE SOGIETÀ SARANNO PRESTO CONFRONTATE A NUOVE SFIDE}

\section{Gilbert DaLgaLian}

Key-words: philosophy, diversity, accepting the Other, challenge, migratory flow, asylum seekers

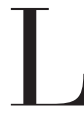

a nostra rivista ha come titolo Educazione e società plurilingui e per definire bene la nostra filosofia questo nome si esprime in due lingue, il francese e l'italiano.

Poiché è proprio una filosofia sotterranea quella che percorre il nostro impegno per le lingue - tutte le lingue - per il plurilinguismo, ma anche per l'apertura culturale e l'accettazione dell'Altro in tutta la sua diversità.

Eppure quest'impegno si urta sempre più contro una sfida gigantesca e mondiale per la quale è meglio essere intellettualmente pronti. Voglio parlare dei flussi migratori, soprattutto in provenienza dell'Africa, ma anche del Vicino Oriente. Essi non potranno evitare di sollecitare in ogni ambito - e, per cominciare, nella nostra rivista una riflessione d'insieme che si situerà in un contesto trasformato, un vero e proprio test per la nostra visione d'una società plurilingue, aperta all'Altro.

Infatti non vi sono ragioni per cui i flussi migratori cessino. Anzi, tutti i parametri indicano che questi flussi diventeranno, in un lasso di tempo più o meno lungo, un maremoto e una questione politica di primaria importanza per tutti i Paesi sviluppati e per l'Unione Europea in particolare.

Ovviamente, non metto nel termine "maremoto" l'idea di sovversione che le estreme destre cercano dappertutto di strumentalizzare per fare dei migranti dei capri espiatori. Si tratta qui di sottolineare l'entità delle migrazioni future.

Perché prevedere un maremoto? Tutte le condizioni sono già presenti e si stanno progressivamente aggravando:

- le siccità e le desertificazioni, la penuria di risorse d'acqua e l'arretramento delle produzioni agricole tradizionali - che il riscaldamento climatico esacerberà ulteriormente, il tutto su uno sfondo di sottosviluppo e di un'esplosione demografica senza precedenti - spingeranno non più migliaia, ma ben presto milioni di Africani e di 
Editoriale: Le nostre società saranno presto confrontate a nuove sfide

G. DALGaLian altri sulle strade dell'esilio.

- le situazioni di guerra civile e/o di dittatura in numerosi Paesi non faranno che aggravare ulteriormente la spinta migratoria. Su questa scala, la distinzione fra migranti economici e richiedenti asilo politico non ha più alcun senso. In forma certo diversa tutte queste migrazioni hanno un fondamento politico.

- la soluzione consistente nello stabilizzare queste popolazioni nel loro Paese tramite un aiuto allo sviluppo - come preconizza il governo francese - arriva decisamente troppo tardi. Se volesse essere efficace, quest aiuto allo sviluppo necessiterebbe più o meno dell'equivalente del bilancio della difesa dell'insieme dell'Unione Europea. Opzione agli antipodi degli orientamenti attuali.

- al contrario, l'Europa ha scelto ovunque di investire sul ripiegamento su di sé e sul consolidamento delle frontiere. Il provvedimento più rivelatore di questa politica antimigratoria è la concessione da parte dell'UE di tre miliardi di euro alla Turchia per stabilizzare i migranti sul suo territorio.

In un contesto di ripiego nazionalista quasi totale, la domanda per la nostra rivista sarà la seguente: come anticipare e accompagnare i flussi migratori? Come aiutare a costruire una strategia d'accoglienza, di sostegno e di formazione di questi uomini, donne e bambini che si staccano con coraggio da un orizzonte di miseria strutturale, ma che i Paesi sviluppati, i nostri governi, non sono pronti ad accogliere?

Avremo le parole, il coraggio, gli argomenti per spiegare ed organizzare l'accoglienza? E questo di fronte alle spinte nazionaliste e demagogiche visibili dappertutto? Dovremo spiegare continuamente che la diversità etnoculturale esige un mutuo rispetto da parte di ciascuno e che questo rispetto deve manifestarsi innanzitutto nell'accettazione delle lingue di ciascuno? Ciò comporta la necessità di insegnarle quando gli effettivi ci sono e una domanda in tal senso viene chiaramente espressa. Ciò esige altresì che l'accesso alle lingue non rinchiuda gli alunni in ghetti, ma sia aperto a tutti i bambini, indipendentemente dalle loro origini. $\mathrm{E}$ che inoltre questi insegnamenti linguistici non siano concepiti in modo da dare adito a forme di comunitarismo. Il principio di laicità si basa su due esigenze: il rispetto della diversità, ma anche l'accesso ai vantaggi - linguistici e culturali - di tale diversità.

In ogni caso la scelta sarà fra un ritorno dell'etnocentrismo più o meno estremo ed il difficile cammino verso una società arcobaleno, l'unica via d'uscita per umanisti consapevoli dell'unicità della specie umana e portatori di solidarietà vitali.

Trad.: Stefano Corno 